\title{
ABCA 3 mutation associated childhood Interstitial Lung Disease (chILD) presenting as Combined Pulmonary Fibrosis and Emphysema in siblings.
}

\author{
Manjit Tendolkar ${ }^{1}$, Rahul Tyagi ${ }^{1}$, and Ajay Handa ${ }^{1}$ \\ ${ }^{1}$ Indian Naval Hospital Ship Asvini
}

December 20, 2020

\begin{abstract}
Childhood interstitial lung diseases (chILD) are a rare presentation. We report case of siblings diagnosed with combined pulmonary fibrosis and emphysema (CPFE) attributable to ABCA 3 mutation. It highlights the progressive nature of the disease as it unfolds itself in both the siblings at around the same age. This is the second case of chILD with CPFE reported in literature and the first evidence of its occurrence in siblings adds to the novelty.
\end{abstract}

\section{Hosted file}

Manuscript.pdf available at https://authorea.com/users/383900/articles/499716-abca-3mutation-associated-childhood-interstitial-lung-disease-child-presenting-as-combinedpulmonary-fibrosis-and-emphysema-in-siblings

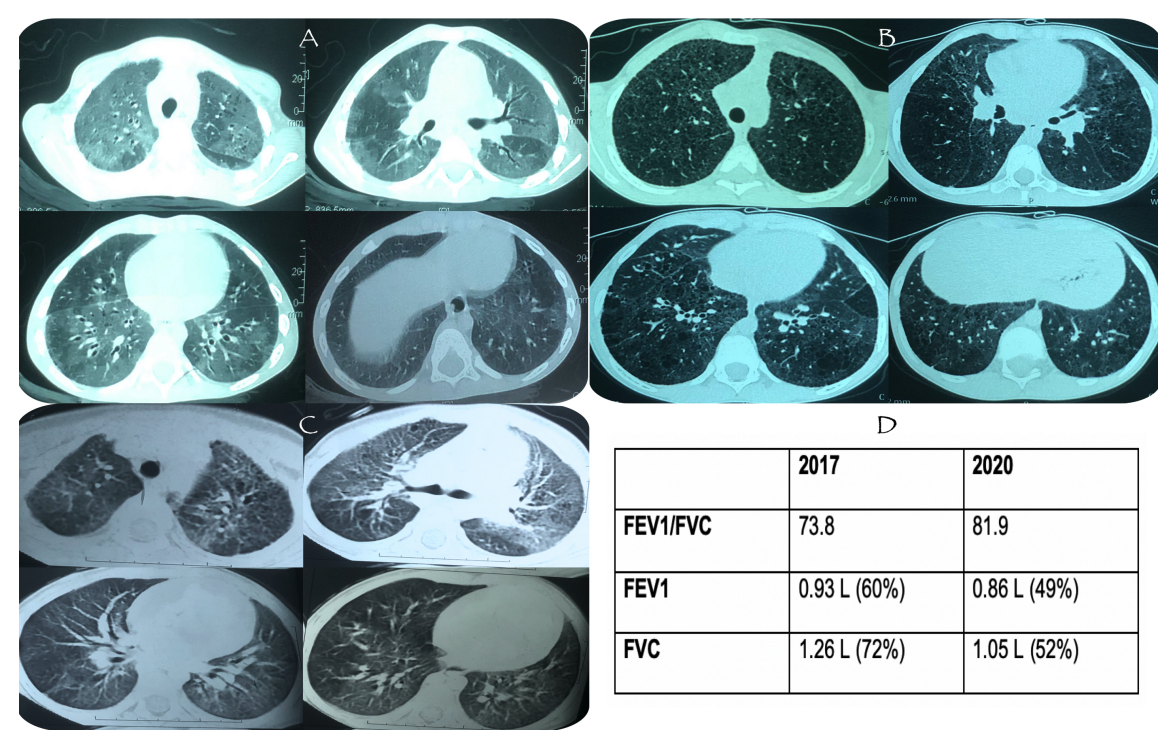

